\title{
(2) OPEN ACCESS \\ Extreme preterm birth in the right place: a quality improvement project
}

\author{
Katherine Edwards, ${ }^{1}$ Lawrence Impey (D) ${ }^{2}$
}

'Patient Safety Collaborative, Oxford Academic Health

Sciences Network, Oxford, UK 2Department of Fetal Medicine Oxford University Hospitals NHS Trust, Oxford, UK

\section{Correspondence to} Lawrence Impey, Oxford University Hospitals NHS Trust, Oxford, Oxfordshire OX4 4GA UK:

Lawrence.impey@ouh.nhs.uk

Received 15 June 2019 Revised 23 October 2019

Accepted 30 October 2019 Published Online First 12 November 2019

Check for updates

(C) Author(s) (or their employer(s)) 2020. Re-use permitted under CC BY-NC. No commercial re-use. See rights and permissions. Published by BMJ.

To cite: Edwards K, Impey L. Arch Dis Child Fetal Neonatal Ed 2020;105:F445-F448.

\begin{abstract}
Extreme preterm birth is a major precursor to mortality and disability. Survival is improved in babies born in specialist centres but for multiple reasons this frequently does not occur. In the Thames Valley region of the UK in 2012-2014, covering 27000 births per annum, about $50 \%$ of extremely premature babies were born in a specialist centre. Audit showed a number of potential areas for improvement. We used regional place of birth

\section{What is already known on this topic?}

In utero transfer to a unit with a neonatal intensive care unit improves neonatal outcomes for preterm neonates.

- In utero transfer rates differ widely according to geographical area and many require improvement.
\end{abstract} data and compared the place of birth of extremely premature babies for 2 years before our intervention and for 4 years (2014-2018) after we started. We aimed to improve the proportion of neonates born in a specialist centre with three interventions: increasing awareness and education across the region, by improving and simplifying the referral pathway to the local specialised centre, and by developing region-wide guidelines on the principal precursors to preterm birth: preterm labour and expedited delivery for fetal growth restriction. There were 147 eligible neonates born within the network in the 2 years before the intervention and 80 (54.4\%) were inborn in a specialised centre. In the 4 years of and following the intervention, there were 334 neonates of whom 255 were inborn (76.3\%) (relative risk of nontransfer 0.50 (95\% Cl 0.39 to 0.65), p<0.001). Rates showed a sustained improvement. The proportion of extremely premature babies born in specialist centres can be significantly improved by a region-wide quality improvement programme. The interventions and lessons could be used for other areas and specialties.

\section{INTRODUCTION}

Preterm birth is a major precursor to neonatal death and lifelong disability. Marked improvements in survival rates ${ }^{1}$ have been made in the last 10 years with intensive care. Extremely preterm infants have higher survival rates if born in a specialised centre with a neonatal intensive care unit (NICU, Level 3 unit). ${ }^{2-6}$ Therefore in utero transfer (IUT) of those pregnancies at imminent risk of extreme preterm birth (in the UK defined as $<27$ weeks, twins $<28$ weeks and where the estimated fetal weight is $<800 \mathrm{~g}$ ), is recommended and in the UK is used as a measure of quality. ${ }^{7}$ Considerable variation among networks exists both internationally ${ }^{3}$ and in the UK: ${ }^{8}$ the Thames Valley region was performing particularly poorly with respect to the rest of the UK, such that in 2012-2014 only half of such babies were born in a unit with an NICU.

Prior to this study, using data from the local neonatal network (Thames Valley and Wessex Neonatal Operational Delivery Network (ODN)), an audit was conducted of all births for the period

\section{What this study adds?}

- In utero transfer rates can be considerably improved with a region-wide quality improvement project.

1 April 2012 and 31 March 2014 in the region where, according to the above criteria, birth should have taken place in a unit with an NICU. Case notes were examined to determine whether transfer could have been possible and to identify barriers to such transfer. Of 146 neonates meeting criteria for transfer, 67 (45.9\%) were outborn, yet postnatal transfer occurred in 91\%. Allowing for multiple pregnancies, 44 of $54(82 \%)$ sets of notes were available and reviewed. In 38 cases (72\%) IUT was not attempted (72\%), yet could reasonably have been possible in at least $18(47 \%)$ of cases. In the six $(13.6 \%)$ cases where an IUT was attempted, inefficiency of the referral pathway prevented it. Principal barriers to transfer were a poorly defined patient pathway, and lack of clinician awareness of the criteria for, and benefits of, birth in a unit with an NICU.

The aim of this quality improvement project was to improve rates of birth of extreme preterm neonates in the unit with an NICU, and therefore their survival chances, by improving IUT rates within the region. The aim of this report is to describe and inform, using standards for quality improvement excellence (SQUIRE) 2.0 guidelines $^{9}$ how this could be achieved.

\section{METHODS}

The Thames Valley area has approximately 27000 births per year, with five maternity care providers including one with a Level 3 neonatal intensive care unit (NICU), four units with Level local neonatal unit (LNU)/special care baby unit (SCBU), and a fifth small unit with an SCBU only which closed in 2016. Tertiary maternity and neonatal intensive care have been provided at one unit since 01 April 2012. The project team was headed by the Chair 
(LI), and manager (KE) of the region-wide maternity network, and consisted of senior midwifery and obstetric representatives from each maternity unit, and the local neonatal ODN and postgraduate obstetric training leads.

Three principal interventions were used:

\section{Intervention 1}

This aimed to increase awareness of the need for and benefits of IUT. We hypothesised that clinicians had limited awareness of policy, of the improved outcomes in NICUs, and required further assurances around the safety of transfer. The unit representatives were encouraged to address these on an individual basis. We intentionally generated considerable local publicity with our baseline audit started in March 2014, and then by presenting at regional events and specialist trainee teaching. The audit findings were formally published in April 2015 with a follow-up report in July 2016. From Jan 2015, the project team was alerted to all postnatal transfers by the neonatal ODN lead and in specific cases informally investigated and fed back issues surrounding non-transfer.

\section{Intervention 2}

This aimed to make IUT easier to arrange. We hypothesised that by making referral more simple and consistent and a default policy of acceptance of appropriate pregnancies, transfer should be more frequent and rapid. We developed a simplified and robust process for arranging IUT. The key principles of the policy were a single point of contact for agreeing and arranging IUTs, 24 hours a day (the Labour Ward consultant obstetrician on duty at the unit with a NICU) and a default policy of acceptance, which could be overridden only by the senior neonatologist or obstetrician on duty. The policy was circulated to all units in January 2015, although key elements were in use earlier.

\section{Intervention 3}

This aimed to improve care by developing region-wide guidelines on the management of clinical scenarios frequently culminating in extreme preterm birth. We hypothesised that where management of these was best practice, was clear and consistent between units, and contained criteria for transfer, appropriate transfer would be more likely to be requested. Simple, singlepage guidelines covering threatened severe preterm labour, preterm rupture of membranes, use of magnesium sulfate and preterm growth restriction, were implemented at each unit in the region. The guidelines were developed using a collaborative testing approach and aligned with, and used as appendices for, relevant existing local guidelines. Development of these guidelines supported Intervention 1 , but they were only finally implemented in July 2015.

Thames Valley and Wessex Operational Delivery Neonatal Network data were used to assess the percentage of neonates meeting criteria for IUT delivered in the Thames Valley region who were inborn (in the unit with an NICU) over six financial years. The percentage of inborn neonates in the 2 years before and the 4 years following the start of the interventions were compared using relative risk (RR) (MedCalc, https://www. medcalc.org) with 95\% CIs. A statistical process control (SPC) chart ${ }^{10}$ was created. Because of the multiple units involved we were unable to determine the numbers of pregnancies where criteria for transfer were met, but extreme preterm delivery did not occur. For the duration of the project, qualitative data on barriers, clinicians' attitudes and potential adverse effects were recorded ad hoc.

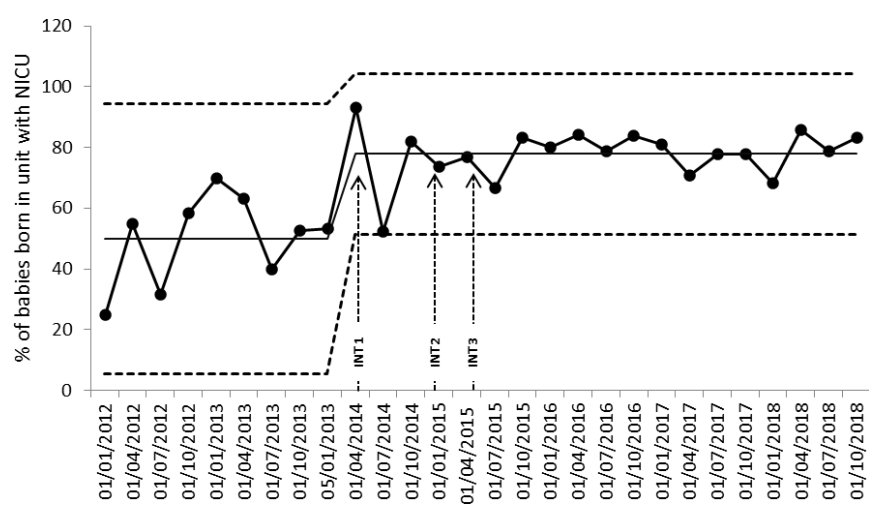

Figure 1 Statistical process control (SPC) chart for extremely preterm neonates born into a neonatal intensive care unit (NICU) in the Thames Valley Region, UK 2012-2018. Quarterly percentage of births in NICU with interventions. Intervention 1: Awareness, training and communication; Intervention 2: Referral pathway; Intervention 3: Region-wide guidelines. Solid thin line: mean for time before (49.89\%) and from the start (77.84\%) of interventions. Dashed lines: upper and lower control limits: $+3 \sigma /-3 \sigma(S D)$.

\section{RESULTS}

Over a 6-year time period there were preterm 481 births in the region where criteria for NICU birth were met, 147 before the start of the interventions and 334 from their inception. In the first 2 years, $80(54.4 \%)$ were inborn; in the following 4 years, $255(76.3 \%)$ were inborn (RR of outborn 0.72 (95\% CI 0.0 .61 to 0.84$), \mathrm{p}<0.001)$. The quarterly figures over the 6 years are displayed as an SPC chart in figure 1. There was considerable quarterly variation in 2012-2014; an increase, that is sustained, in numbers of inborn neonates follows the start of work on Intervention 1 . Table 1 shows annual figures, divided according to the criteria for IUT. In only two cases did IUT fail once attempted (due to unit capacity); our audit had shown six cases before the interventions.

Although not formally measured, a number of other effects were observed. Staff in local units were, and remain, anxious about transfer of labouring women although there were no cases of birth during transfer for the entire time period. A considerable increase in the maternity workload in the unit with an NICU was noted. This included referrals of women with 'previable' pregnancies. Women with threatened preterm birth who did not deliver after 24 hours were noted to be more likely to remain as inpatients for longer than local women would have done, possibly due to concern of delivering in their local units. At least two cases were observed where transferred women were discharged, undelivered, from the unit with an NICU but delivered days after at their local unit. In addition, some women requested permanent transfer of care despite reaching a gestation or birth weight suitable for a non-NICU birth.

\section{DISCUSSION}

This report demonstrates the considerable and sustained increase in neonates 'born in the right place' in association with a regionwide quality improvement project. The principal improvement coincided with the start of Intervention 1: increasing awareness among maternity and neonatal staff of Level 2 units of the benefits of delivery in a unit with an NICU for extreme preterm babies. This suggests that this was the key part of the improvement. Developing the referral system and region-wide guidelines also improved awareness and may have stabilised referral, but we did not see further improvements following 
Table 1 Births of extremely preterm neonates within the Thames Valley region

\begin{tabular}{|c|c|c|c|c|c|c|}
\hline & 2012-2013 & 2013-2014 & 2014-2015 & 2015-2016 & 2016-2017 & 2017-2018 \\
\hline Financial year & $\mathrm{N}(\%)$ & $\mathrm{N}(\%)$ & N (\%) & $\mathrm{N}(\%)$ & $\mathrm{N}(\%)$ & $\mathrm{N}(\%)$ \\
\hline Birth within TV network & 71 & 76 & 79 & 77 & 90 & 88 \\
\hline IUT to Level 3 unit from outside network* & 7 & 4 & 9 & 4 & 9 & 2 \\
\hline Booking and birth within TV network $†$ & 64 & 72 & 70 & 73 & 81 & 86 \\
\hline Birth in Level 3 unit within networkł & $35(54.6)$ & $34(47.2)$ & $49(70)$ & $54(73.9)$ & $65(80.2)$ & $63(73.3)$ \\
\hline Birth in Level $1 / 2$ unit within network $\ddagger$ & $29(45.3)$ & $38(52.7)$ & $21(30)$ & $19(26)$ & $16(19.8)$ & $23(26.7)$ \\
\hline$<27$ weeks, single & $15(51.7)$ & $20(52.6)$ & $12(57.1)$ & $10(52.6)$ & $10(62.5)$ & $18(78.3)$ \\
\hline$\geq 27$ weeks, $<800 \mathrm{~g}$, single & 4 (13.8) & $3(7.9)$ & $4(19.0)$ & $3(15.8)$ & $2(12.5)$ & $3(13.0)$ \\
\hline$<28$ weeks, multiple & $7(24.1)$ & $14(36.8)$ & $5(23.8)$ & $6(31.6)$ & $4(25.0)$ & $2(8.7)$ \\
\hline$\geq 28 \mathrm{w}_{1}<800 \mathrm{~g}$, multiple & $3(10.3)$ & $1(2.6)$ & 0 & 0 & 0 & 0 \\
\hline
\end{tabular}

${ }^{*}$ A small number of IUTs occurred to the Level 3 unit from outside the region.

†All births within the network excluding women who were transferred from outside the network.

¥The numbers and proportions of births using booked and birthing within the network.

IUT, in utero transfer; TV, Thames Valley.

their formal introduction. The strength of this project was the use of a detailed audit to inform reasons behind non-transfer, and the network-led, region-wide, collaborative approach to the interventions. In England, Local Learning Systems, as part of the Maternal and Neonatal Health Safety Collaborative, are forming to provide a similar type of regional network, including both obstetric and neonatal staff, which could facilitate improvement in a similar fashion.

There is good evidence that maximising the number of extremely preterm neonates born in a unit with an NICU could reduce morbidity and mortality. A meta-analysis in $2010^{3}$ showed increased death rates for very low birthweight neonates born outside of units with an NICU (38\% vs 23\%; adjusted OR (aOR) 1.62 (95\% CI 1.44 to 1.83$)$ ). In a prospective national Canadian cohort study of children born between 2009 and 2011 at $<29$ weeks, site was an independent determinant of both neurodevelopmental outcome and death. ${ }^{4}$ Among livebirths between 22 weeks and 27 weeks in Australia, ${ }^{5}$ rates of periventricular leukomalacia were increased (aOR 5.34 (95\% CI 1.84 to 15.54)) among outborn compared with inborn neonates. In-hospital mortality of neonates born before 27 weeks in the UK is lowest in babies born in high volume neonatal units (instrumental variable regression OR 0.51 (95\% CI 0.33 to 0.79$)){ }^{6}$ Analysis of the EPICURE cohort of 2460 neonates born at 22-26 weeks ${ }^{2}$ showed that birth in a unit with an NICU, as opposed to a lower level unit, was associated with a lower overall mortality (aOR 0.73 (95\% CI 0.59 to 0.90$)$ ). Neonates not transferred in utero had higher rates of death than those transferred (aOR 1.44 (95\% CI 1.09 to 1.90$)$ ) and death rates did not differ among those transferred in utero and those booked and born in units with an NICU (aOR 1.08 (95\% CI 0.83 to 1.41$)$ ). Contrary to expectations, delivery during IUT is very rare. ${ }^{11}$

There are antenatal benefits to IUT. Marlow et al demonstrated increased odds of antenatal death (aOR $1.52 \quad(95 \%$ CI 1.03 to 2.26$)$ ) in pregnancies not transferred into a NICU service. There were pregnancies in our cohort where antenatal transfer occurred for iatrogenic delivery owing to concerns over fetal state, but ultimately delivery was not immediately expedited in the unit with NICU facilities such that by the time of birth the neonate did not meet inclusion criteria for IUT.

In the UK in 2017 inborn rates for babies less than 27 weeks in different regions varied between $46.4 \%$ and $89.7 \%$, with a mean of $73.9 \% .^{8}$ Considerable variation also exists in other countries. $^{3}$ More than 2 years after the start of our interventions, our figures were only slightly better than the UK mean. It is unclear which factors determine transfer rates, and region size does not appear to be important. ${ }^{8}$ It is likely that the number of units with an NICU and the distances between units are important; our data suggest, at least in areas with low transfer rates, that awareness may be a problem. IUT is difficult to arrange; ${ }^{12}$ and may not be possible: in an analysis of extreme/severe preterm birth occurring outside an NICU unit in France only 6/31 were classified as avoidable. ${ }^{13}$ Further improvement is needed to achieve a national target level of $85 \%$, met in 2017 by only two regions in England. ${ }^{8}$ Although we have not formally collected data, it is our impression that this will only be achievable if a lower threshold for transfer of labouring women is used and staff are reassured that, overall, the benefits of birth in a unit with an NICU are likely to be greater than the low risk of birth ${ }^{11}$ during transfer. The cost implications, financial and emotional, of IUT are complex. A large number of women meeting criteria for IUT will not deliver preterm. The current system of maternity payment, at least in the UK, is unlikely to appropriately compensate maternity services with an NICU. On a wider scale, however, transfer is highly likely to be cost-effective. Negative parental experience of IUT $^{14}$ should be set against experience of postnatal transfer. ${ }^{15}$ There are limitations to this report. It is likely that some improvement in IUT rates would have occurred without the project. As with many analyses of outcomes by place of birth, neonates who died before admission to a neonatal unit were excluded. A small number of IUTs occurred to units outside the region and therefore do not appear in Thames Valley data; equally there were a small number (2-9 per annum) of IUTs to the unit with an NICU from outside the region. The number of these did not alter significantly over the time period (table 1) and they are not included in our analysis. We are also limited by absence of data on which criteria for transfer were met in these babies, meaning we cannot meaningfully analyse improvement for each transfer criterion, for example, for singletons versus multiple pregnancies. We also do not have numbers of total IUTs that include those who did not deliver extremely preterm, nor data on other collateral effects of increased transfer rates. In common with other quality improvement projects we are unable to prove causation between our interventions and the observed changes, and our lack of pregnancy or demographic data prevented closer analysis. Finally, we do not have mortality data. Nevertheless a commissioned report by the Office of Health Economics and RAND Europe ${ }^{16}$ calculated that two to four deaths per annum should be prevented by this increase. 
Place of birth is an important safety issue in maternity care and for extreme preterm neonates is a current priority for NHS England. ${ }^{17}$ We describe a region-wide collaborative project that was followed by considerable improvement of IUT. The interventions used and lessons learnt could be applied to other regions and countries, and across other specialties. Further improvement will be essential to enable the benefits of centralisation to be properly realised and to allow the hub-and-spoke model of care that is central to health policy in the UK and beyond to be most effective.

\section{Twitter Katherine Edwards @KatCEdwards}

Acknowledgements The authors thank Ms Jacqui Bobby and Ms Gina Outram for provision of neonatal data, Dr Eleri Adams and Dr Mark Anthony for technical advice, Ms Rasanat Nawaz for data assistance, Professor Charles Vincent for comments and the Oxford AHSN Maternity Network Steering Group members for their contributions to the project.

Contributors Both authors co-designed the project and report, co-wrote it and have approved the final version. They agree to be accountable for all aspects of the work in ensuring that questions related to the accuracy or integrity of any part of the work are appropriately investigated and resolved.

Funding This quality improvement project was funded by the Oxford Patient Safety Collaborative, Oxford Academic Health Science Network, Magdalen Centre North, Robert Robinson Avenue, Oxford Science Park, OX4 4GA.

Competing interests None declared.

Patient consent for publication Not required.

Ethics approval Information governance agreements were obtained from each unit for the baseline audit. The data on in utero transfer were publicly available and so no formal ethical approval was deemed necessary.

Provenance and peer review Not commissioned; externally peer reviewed.

Data availability statement All data relevant to the study are included in the article or uploaded as supplementary information.

Open access This is an open access article distributed in accordance with the Creative Commons Attribution Non Commercial (CC BY-NC 4.0) license, which permits others to distribute, remix, adapt, build upon this work non-commercially, and license their derivative works on different terms, provided the original work is properly cited, appropriate credit is given, any changes made indicated, and the use is non-commercial. See: http://creativecommons.org/licenses/by-nc/4.0/.

ORCID iD

Lawrence Impey http://orcid.org/0000-0002-4462-112X

\section{REFERENCES}

1 Santhakumaran S, Statnikov Y, Gray D, et al. Survival of very preterm infants admitted to neonatal care in England 2008-2014: time trends and regional variation. Arch Dis Child Fetal Neonatal Ed 2018;103:F208-15.

2 Marlow N, Bennett C, Draper ES, et al. Perinatal outcomes for extremely preterm babies in relation to place of birth in England: the EPICure 2 study. Arch Dis Child Fetal Neonatal Ed 2014;99:F181-8.

3 Lasswell SM, Barfield WD, Rochat RW, et al. Perinatal regionalization for very lowbirth-weight and very preterm infants: a meta-analysis. JAMA 2010;304:992-1000.

4 Synnes A, Luu TM, Moddemann D, et al. Determinants of developmental outcomes in a very preterm Canadian cohort. Arch Dis Child Fetal Neonatal Ed 2017;102:F235-43.

5 Boland RA, Davis PG, Dawson JA, et al. Outcomes of infants born at 22-27 weeks' gestation in Victoria according to outborn/inborn birth status. Arch Dis Child Fetal Neonatal Ed 2017;102:F153-61.

6 Watson SI, Arulampalam W, Petrou S, et al. The effects of designation and volume of neonatal care on mortality and morbidity outcomes of very preterm infants in England: retrospective population-based cohort study. BMJ Open 2014;4:e004856.

7 NICE. Neonatal specialist care, 2010. Available: www.nice.org.uk/guidance/qs4/ chapter/Quality-statement-1-Care-pathways-and-guidelines

8 National Neonatal Audit Programme (NNAP). Annual report 2018 annual report on 2017 data. Royal College of paediatrics and child health, 2018.

9 Ogrinc G, Davies L, Goodman D, et al. SQUIRE 2.0 (Standards for Quality Improvement Reporting Excellence): revised publication guidelines from a detailed consensus process. BMJ Qual Saf 2016;25:986-92.

10 Benneyan JC, Lloyd RC, Plsek PE. Statistical process control as a tool for research and healthcare improvement. Quality and Safety in Health Care 2003;12:458-64.

11 Dupuis O, Arsalane A, Dupont C, et al. [In utero transfer for preterm labor: experience of a regional perinatal hotline providing a 24-hour on call service]. Gynecol Obstet Fertil 2004;32:285-92.

12 Gale C, Hay A, Philipp C, et al. In-utero transfer is too difficult: results from a prospective study. Early Hum Dev 2012;88:147-50.

13 Martin I, Roussel A, Olieric M-F, et al. [Analysis of obstetric-pediatric care in the perinatal period. Are births before 31 weeks' gestation in level $2 B$ maternity units avoidable?]. Arch Pediatr 2017;24:1188-96

14 Porcellato L, Masson G, O'Mahony F, et al. 'It's something you have to put up with'--service users' experiences of in utero transfer: a qualitative study. BJOG 2015;122:1825-32.

15 Aagaard H, Hall EOC, Ludvigsen MS, et al. Parents' experiences of neonatal transfer. A meta-study of qualitative research 2000-2017. Nurs Inq 2018;25:e12231.

16 Marsden G, Martin A, Zamora B. Four case studies to explore the added value of Oxford AHSN. office of health economics Rand Europe. final report, 2016. Available: https://www.ohe.org/publications/four-case-studies-explore-added-value-oxfordahsn

17 NHS England. Saving Babies' Lives Version Two. A care bundle for reducing perinatal Mortality, 2019. Available: https:/www.england.nhs.uk/wp-content/uploads/2019/ 05/saving-babies-lives-care-bundle-version-two.pdf 